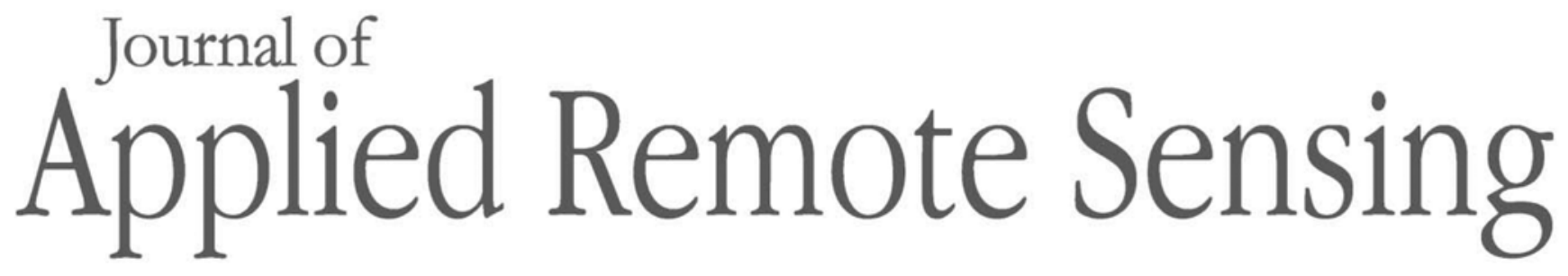

RemoteSensing.SPIEDigitalLibrary.org

\title{
Errata: Effect of detection on spatial resolution in synthetic aperture radar imagery and mitigation through upsampling
}

Khalid El-Darymli

Peter McGuire

Eric Gill

Desmond Power

Cecilia Moloney

\section{SPIE.}




\title{
Errata: Effect of detection on spatial resolution in synthetic aperture radar imagery and mitigation through upsampling
}

\author{
Khalid El-Darymli, ${ }^{\text {a,b }}$ Peter McGuire, ${ }^{\mathrm{c}}$ Eric Gill, ${ }^{\mathrm{b}}$ Desmond Power, ${ }^{\mathrm{c}}$ and \\ Cecilia Moloney ${ }^{\mathrm{b}}$ \\ ${ }^{a}$ Northern Radar, 25 Anderson Avenue, St. John's, Newfoundland, A1B 3E4, Canada \\ ${ }^{b}$ Memorial University, Faculty of Engineering \& Applied Science, St. John's, \\ Newfoundland, A1B 3X5 Canada \\ 'C-CORE, Captain Robert A. Bartlett Building, Morrissey Road, St. John's, \\ Newfoundland, A1C 3X5, Canada
}

[DOI: 10.1117/1.JRS.8.089997]

This article [J. Appl. Remote Sens. 8(1), 083601 (July 25 2014)] contained an error in the abstract that changed the meaning of a sentence. The original sentence read, "It is shown that magnitude and power detections, respectively, degrade the spatial resolution by factors of two and greater." The corrected sentence reads, "It is shown that power and magnitude detections, respectively, degrade the spatial resolution by factors of two and greater."

All online versions of the article were corrected on 31 July 2014. 